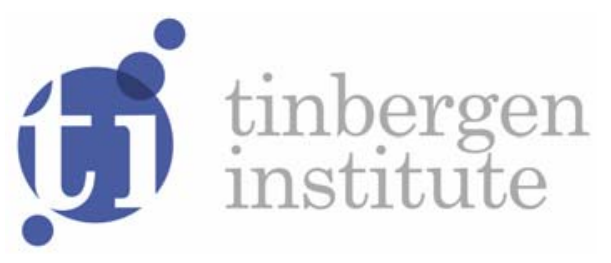

\title{
Model-based Business Cycle and Financial Cycle Decomposition for Europe and the U.S.
}

Siem Jan Koopman',2

Rutger Lit'

André Lucasl,2

' Faculty of Economics and Business Administration, VU University Amsterdam, The Netherlands;

2 Tinbergen Institute, the Netherlands. 
Tinbergen Institute is the graduate school and research institute in economics of Erasmus University Rotterdam, the University of Amsterdam and VU University Amsterdam.

More TI discussion papers can be downloaded at http://www.tinbergen.nl

Tinbergen Institute has two locations:

Tinbergen Institute Amsterdam

Gustav Mahlerplein 117

1082 MS Amsterdam

The Netherlands

Tel.: +31(0)20525 1600

Tinbergen Institute Rotterdam

Burg. Oudlaan 50

3062 PA Rotterdam

The Netherlands

Tel.: +31(0)10 4088900

Fax: +31(0)10 4089031 


\title{
Model-based business cycle and financial cycle decomposition for Europe and the U.S.*
}

\author{
Siem Jan Koopman ${ }^{(a, b)}$, Rutger Lit ${ }^{(a)}$ and André Lucas ${ }^{(a)}$ \\ ${ }^{(a)}$ Vrije Universiteit Amsterdam and Tinbergen Institute \\ ${ }^{(b)}$ CREATES, Aarhus University
}

June 30, 2016

\begin{abstract}
We develop a multivariate unobserved components model to extract business cycle and financial cycle indicators from a panel of economic and financial time series of four large developed economies. Our model is flexible and allows for the inclusion of cycle components in different selections of economic variables with different scales and with possible phase shifts. We find clear evidence of the presence of a financial cycle with a length that is approximately twice the length of a regular business cycle. Moreover, cyclical movements in credit related variables largely depend on the financial cycle, and only marginally on the business cycle. Property prices appear to have their own idiosyncratic dynamics and do not substantially load on business or financial cycle components. Systemic surveillance policies should therefore account for the different dynamic components in typical macro financial variables.
\end{abstract}

Key Words: financial cycle; business cycle; phase shift; multivariate state space model; Kalman filtering; panel time series.

${ }^{*}$ All authors thank the European Union Seventh Framework Programme (FP7-SSH/2007-2013, grant agreement 320270 - SYRTO) for financial support. Koopman also acknowledges support from CREATES, Center for Research in Econometric Analysis of Time Series (DNRF78), funded by the Danish National Research Foundation. 


\section{Introduction}

We introduce a model-based rather than a pure filtering approach to estimate the financial cycle from a panel of economic and financial time series for four large developed economies. The possible existence and dynamics of a financial cycle have gained momentum following the 2008 financial crisis and the subsequent European sovereign debt crisis. Cyclical fluctuations in macro financial variables appear to be not only caused by business cycle fluctuations, but also by other secular swings in financial aggregates. It is widely established that such 'financial cycles' have a typical length between 10 and 30 years, which is substantially longer than a typical business cycle. Therefore, estimating the dynamics of such cycles is an important step in surveilling systemic stability.

Recent contributions in the extraction of the financial cycle from economic and financial variables are given by, among others, Claessens, Ayhan Kose, and Terrones (2011), Borio (2014), Strohsal, Proaño, and Wolters (2015), Drehmann, Borio, and Tsatsaronis (2012), and Galati, Hindrayanto, Koopman, and Vlekke (2016). We refer to Galati et al. (2016) for an elaborate introduction and review of the financial cycle literature. Many of the papers on the financial cycle use standard non-parametric detrending techniques from the macroeconomics literature to estimate the cycle, such as the well-known decomposition method of Hodrick and Prescott (1980) or the so-called band-pass filters of Baxter and King (1999) and Christiano and Fitzgerald (2003). These filters are typically formulated in the frequency domain (spectral analysis). An alternative to these non-parametric detrending techniques is the econometric model-based approach to a trend-cycle decomposition as developed within the autoregressive integrated moving average (ARIMA) modeling literature; see, for example, Beveridge and Nelson (1981) and Morley, Nelson, and Zivot (2003).

Our contribution is to develop an econometric, model-based decomposition framework for the extraction of the business cycle and financial cycle using a panel of macro financial time series. For this purpose, we adopt the unobserved components time series (UCTS) model, or structural time series model, of Harvey (1989); see also Clark (1987), Harvey and Jaeger (1993) and Harvey and Trimbur (2003) for a complete econometric treatment of trend-cycle decompositions within the UCTS framework. Our approach is explicitly multivariate in nature and builds on the work presented in Galati et al. (2016). In particular, we consider larger panels of economic and financial variables and we allow the common (business and financial) cycles to be shifted to the right or left in each individual variable of the panel. Within the UCTS approach, especially when compared to semi-nonparametric detrending methods or even to ARIMA-based approaches, it is rather convenient to extend the econometric analysis into a multivariate framework with interesting features such as shifting cycles. A success- 
ful exemption is the multivariate band-pass filter of Valle e Azevedo (2011). Multivariate generalization of the UCTS framework for extracting business cycles is developed by Valle e Azevedo, Koopman, and Rua (2006). Such methods can also be used to simultaneously extract the business cycle and financial cycle from a panel of time series.

We apply our multivariate model to a panel of macro financial variables including most of the typical variables used to estimate the financial cycle. The variables include gross domestic product (GDP), credit related variables, and property prices. We perform our analysis for four main developed economies: the United States, Germany, France, and the United Kingdom. To account for the possibility that the business cycle and financial cycle may affect each of these variables differently, our model set-up allows for different amplitudes and different lead/lag relationships of the cycles across the different variables. The lead/lag relationships are estimated implicitly by adopting the phase shift methodology of Rünstler (2004), which is applicable to stochastic cyclical processes. Furthermore, the cycle lengths are not fixed ex-ante but are estimated from the data. The UCTS model can conveniently be formulated in a linear state space form and the parameters can be estimated using standard maximum likelihood and Kalman filtering methods; see Harvey (1989) and Durbin and Koopman (2012).

We find clear evidence of a financial cycle above and beyond business cycle movements for the countries in our sample, with the exception of Germany. The financial cycle typically has twice the length of the business cycle and is in line with the 10-30 year range that is reported in earlier studies; see Galati et al. (2016) and the references therein. Interestingly, the financial cycle explains most of the cyclical movements in the credit related variables in our sample. Using the level of credit, the credit-to-GDP, and the credit-to-disposablepersonal-income (DPI) ratios, the financial cycle explains more than $79 \%$ of the cyclical variation in these variables, the remainder being captured by the business cycle. For the credit-to-GDP and credit-to-DPI ratios, the business cycle even captures less than $6 \%$ of the cyclical movements. This underlines the importance of keeping track of financial cycle movements in systemic stability surveillance, as business cycle fluctuations alone do not capture the full dynamic pattern of the macro finance environment.

Another important finding of our empirical analysis is that property prices appear to follow their own dynamic pattern. Property prices only react marginally to business cycle and financial cycle fluctuations. To replicate financial cycle patterns from the literature, the trend components in property prices have to be restricted to be sufficiently rigid. If such restrictions are relaxed, the data indicate that the dynamic pattern in property prices deviates substantially from that in GDP or in the credit related variables. Relaxing these 
assumptions is possible in our model-based framework. However, some caution should be taken when property prices are mixed with credit information to estimate a financial cycle.

The extraction of financial cycles from economic and financial time series stands in a much longer tradition in the literature on business cycle extraction; see, for example, Stock and Watson (1999) for a review of the literature, Krolzig (1997) for a multivariate approach using switching regime vector autoregressive (VAR) models, and Sims (1980) and Bernanke and Blinder (1992) for seminal references to the structural VAR literature for analyzing and extracting business cycles.

The remainder of this paper is organized as follows. We describe the data in Section 2. The multivariate unobserved components time series model with common cycles and phase shifts is explained in Section 3. Results are presented in Section 4. Section 5 concludes.

\section{Data}

To construct our panel data set of quarterly economic and financial time series, we follow the predominant choice of variables in the financial cycle literature and include Credit, Credit-toGDP, Credit-to-Disposable Personal Income (Credit-to-DPI), and residential property prices (Property). For the use of these and similar variables, see for example Claessens et al. (2011), Drehmann et al. (2012), Strohsal et al. (2015), and Galati et al. (2016). In addition to these credit and price related variables, we include GDP to represent the business cycle and isolate the financial cycle.

Credit data are provided by the Bank for International Settlements. ${ }^{1}$ The variable measures the outstanding amount of credit at the end of each quarter. Credit covers core debt, i.e., loans, debt securities and currency and deposits. Disposable Personal Income and GDP are obtained from the research website of the Federal reserve bank of St. Louis ${ }^{2}$ for the U.S., and from Datastream for the other countries. Nominal property prices are also obtained from the Bank of International Settlements. ${ }^{3}$ House prices are typically included in analyses on the financial cycle. One of the typical economic sectors where excess credit can settle in case of an upward financial cycle is housing. Excess credit may lead to excess demand on the housing market, which under inflexible supply, has an effect on house prices and therefore may be reflective of a financial cycle being active. Such cyclical movements may be systemically distortive, such that it is important to get a clear signal of whether such cycles are effective or not.

\footnotetext{
${ }^{1}$ 'BIS total credit statistics', http://www.bis.org/statistics/totcredit.htm.

${ }^{2}$ See https://research.stlouisfed.org/.

${ }^{3}$ See http://www.bis.org/statistics/pp.htm.
} 
If possible, real (constant price) time series are considered, expressed in billions of the domestic currency. For nominal series, the series are first deflated by the Consumer Price Index (CPI, all items) of the respective country. Also, if series are not seasonally adjusted, we apply the X12-ARIMA filter for seasonal adjustment. Finally, we take natural logarithms to remove (potentially) exponential growth patterns and to approximately linearize the series. The Credit-to-GDP and Credit-to-DPI series are ratios and are therefore not expressed in logs. The length of each time series in the panel is determined by data availability. Hence we are analyzing unbalanced panels of data. For example, data for GDP are typically more abundant than for property prices. Our final sample comprises the period 1970-2014.

\section{Multivariate unobserved components model}

Let $\boldsymbol{y}_{t}=\left(y_{1 t}, \ldots, y_{p t}\right)^{\prime}$ be a vector of observations at time $t$ with elements $y_{i t}$ for $i=1, \ldots, p$ and $t=1, \ldots, n$. To obtain our trend-cycle decomposition, we use the model

$$
y_{i t}=\mu_{i t}+\delta_{i} \psi_{\mathrm{BC}, t}+\beta_{i} \psi_{\mathrm{FC}, t}+\varepsilon_{i t}, \quad \varepsilon_{i t} \stackrel{i i d}{\sim} \mathrm{N}\left(0, \sigma_{\varepsilon, i}^{2}\right)
$$

where $\mu_{i t}$ represents a series-specific trend component for series $i$, and $\psi_{\kappa, t}, \kappa \in\{\mathrm{BC}, \mathrm{FC}\}$ represent the two stochastic cycles (BC for business cycle and FC for financial cycle) which are common to all series in $\boldsymbol{y}_{t}$. The BC and FC cycles are intended to capture the respective medium-term business cycle and long-term financial cycle dynamics. The contributions of the $\mathrm{BC}$ and $\mathrm{FC}$ cycles to the $i$ th time series variable $y_{i t}$ are determined by the loadings $\delta_{i} \geq 0$ and $\beta_{i} \geq 0$, respectively. The non-negative restrictions are imposed for convenience and interpretation since we also introduce possible phase shifts in the cycles between the series in $\boldsymbol{y}_{t}$; see Section 3.1. The individual disturbance term, or also referred to as the irregular component, $\varepsilon_{i t}$ is assumed to be normally distributed and serially and cross-sectionally uncorrelated, that is across $i$ and $t$. Seasonal components could also be added to the decomposition in (1) as in Harvey (1989) and Durbin and Koopman (2012). Since we focus on extracting cycles, we do not consider seasonal components here and instead use the X12ARIMA filter for the seasonal adjustment the time series, prior to the modelling task.

Cycles are typically viewed as temporal deviations from a long-term trend. In order to provide some space for the cycle component to make an impact on $y_{i t}$, we impose a certain level of smoothness to the trend component. For this purpose, we specify it as a local linear trend that is given by

$$
\begin{aligned}
& \mu_{i, t+1}=\mu_{i t}+\nu_{i t}, \\
& \nu_{i, t+1}=\nu_{i t}+\xi_{i t}, \quad \xi_{i t} \stackrel{i i d}{\sim} \mathrm{N}\left(0, \sigma_{\xi, i}^{2}\right),
\end{aligned}
$$


where $\nu_{i t}$ represents the gradient of the trend component $\mu_{i t}$ and is often referred to as the growth or slope term; see Harvey (1989), Durbin and Koopman (2012) and the references therein. The disturbance term $\xi_{i t}$ is assumed to be serially and cross-sectionally uncorrelated and independent of $\varepsilon_{i t}$, contemporaneously and for all leads and lags. Further smoothness for the trend component can be introduced in this specification and is discussed in detail by Harvey and Trimbur (2003).

The stochastic cycle components $\psi_{\mathrm{BC}, t}$ and $\psi_{\mathrm{FC}, t}$ are modelled as stationary dynamic processes and are formulated by the trigonometric specification

$$
\left(\begin{array}{c}
\psi_{\kappa, t+1} \\
\psi_{\kappa, t+1}^{\star}
\end{array}\right)=\phi_{\kappa}\left[\begin{array}{cc}
\cos \lambda_{\kappa} & \sin \lambda_{\kappa} \\
-\sin \lambda_{\kappa} & \cos \lambda_{\kappa}
\end{array}\right]\left(\begin{array}{c}
\psi_{\kappa, t} \\
\psi_{\kappa, t}^{\star}
\end{array}\right)+\left(\begin{array}{c}
\omega_{\kappa, t} \\
\omega_{\kappa, t}^{\star}
\end{array}\right), \quad\left(\begin{array}{c}
\omega_{\kappa, t} \\
\omega_{\kappa, t}^{\star}
\end{array}\right) \stackrel{i i d}{\sim} \mathrm{N}\left(0,\left[\begin{array}{cc}
\sigma_{\omega, \kappa}^{2} & 0 \\
0 & \sigma_{\omega, \kappa}^{2}
\end{array}\right]\right),
$$

for $\kappa \in\{\mathrm{BC}, \mathrm{FC}\}$, where the frequency of the cycle $\lambda_{\kappa}$ is measured in radians with $0 \leq$ $\lambda_{\kappa} \leq \pi$ leading to a period of the stochastic cycle of $2 \pi / \lambda_{\kappa}$. The persistence parameter $\phi_{\kappa}$ is restricted within the interval $0<\phi_{\kappa}<1$ to ensure a stationary process for the cycle. The disturbances $\omega_{i t}$ and $\omega_{i t}^{\star}$ are mutually, serially, and cross-sectionally uncorrelated and independent of all other disturbances in the model. The unconditional variance of the cycle is $\sigma_{\psi_{\kappa}}^{2}=\sigma_{\omega_{\kappa}}^{2} /\left(1-\phi_{\kappa}^{2}\right)$, such that $\psi_{\kappa, 1} \stackrel{i i d}{\sim} \mathrm{N}\left(0, \sigma_{\psi_{\kappa}}^{2}\right)$ and $\psi_{\kappa, 1}^{\star} \stackrel{i i d}{\sim} \mathrm{N}\left(0, \sigma_{\psi_{\kappa}}^{2}\right)$ for $\kappa \in\{\mathrm{BC}, \mathrm{FC}\}$. This cycle specification is somewhat stylized but the parameters have clear interpretations. Also, it can be shown that this cyclical dynamic process for $\psi_{\kappa, t}$ can be specified as a stationary autoregressive moving average (ARMA) process with an autoregressive lag polynomial with complex roots.

In our decomposition model (1), all time series variables in the panel only share two common cycles. The trend and irregular components are specific to each equation in the panel; these two components are truly idiosyncratic. In our specification, we do not impose the trend, cycle and irregular components to each time series. For example, when a time series in $\boldsymbol{y}_{t}$ does not exhibit trend behaviour, the variance $\sigma_{\xi, i}^{2}$ of the slope term $\nu_{i t}$ can be set to zero so that $\nu_{i t}$ reduces to a constant (possibly zero, depending on its initial condition) and $\mu_{i t}$ reduces to a constant (when the slope is zero) or a fixed time trend. Similarly, in case variance $\sigma_{\varepsilon, i}^{2}$ is zero, the irregular component $\varepsilon_{i t}$ will vanish from the model equation (1). When a series does not exhibit cyclical behaviour (or only the BC or FC parts of it), this can be accounted for by putting either $\delta_{i}$ and/or $\beta_{i}$ to zero. Finally, in order to identify the scales of the BC and FC cycles by means of the variance $\sigma_{\omega, \kappa}^{2}$, we set one of the loadings $\delta_{i}$ and one of the loadings $\beta_{j}$, across $i, j=1, \ldots, p$, to unity. The scale of the cycle is then associated with the variable to which this restriction applies. 


\subsection{Phase shifts}

A further flexibility in the model equation (1) is introduced by letting the, say, business cycle component in one variable $i$ lead or lag those in another variable $j$. We do the same for the financial cycle. Such an individual shift of the cycle in each equation accounts for the possibility that the cyclical behaviour in one series is the same as in another series but only the timing is different: the cycle in variable $i$ leads the same cycle (possibly with a different scale) in variable $j$, or vice-versa. This shifting can also be relevant for the financial cycle component. To introduce this flexibility in our model, we adopt the phase shift methodology of Rünstler (2004) and replace the decomposition model equation (1) by the model specification

$$
\begin{aligned}
y_{i t} & =\mu_{i t}+\delta_{i} \psi_{\mathrm{BC}, i t}+\beta_{i} \psi_{\mathrm{FC}, i t}+\varepsilon_{i t}, \quad \varepsilon_{i t} \stackrel{i i d}{\sim} \mathrm{N}\left(0, \sigma_{\varepsilon, i}^{2}\right), \\
\psi_{\mathrm{BC}, i t} & =\cos \left(\gamma_{\mathrm{BC}, i} \lambda_{\mathrm{BC}}\right) \psi_{\mathrm{BC}, t}+\sin \left(\gamma_{\mathrm{BC}, i} \lambda_{\mathrm{BC}}\right) \psi_{\mathrm{BC}, t}^{\star}, \\
\psi_{\mathrm{FC}, i t} & =\cos \left(\gamma_{\mathrm{FC}, i} \lambda_{\mathrm{FC}}\right) \psi_{\mathrm{FC}, t}+\sin \left(\gamma_{\mathrm{FC}, i} \lambda_{\mathrm{FC}}\right) \psi_{\mathrm{FC}, t}^{\star},
\end{aligned}
$$

where the components $\mu_{i t}, \psi_{\mathrm{BC}, i t}, \psi_{\mathrm{FC}, i t}$ and $\varepsilon_{i t}$ are introduced and discussed above. This modelling framework is similar to Valle e Azevedo et al. (2006) where the phase shift is introduced for a single common cycle. In our modelling framework we have two cyclical components, BC and FC, in series $i$ that are shifted by $\gamma_{\mathrm{BC}, i}$ and $\gamma_{\mathrm{FC}, i}$ periods, respectively. The phase shift coefficients $\gamma_{\mathrm{BC}, i}$ and $\gamma_{\mathrm{FC}, i}$ are measured in radians with $0 \leq \lambda_{\kappa} \leq \pi$ and are treated as parameters which can be either positive or negative. When positive, the cycle for series $i$ is shifted to the left (and it is leading the base cycle) and when negative, the cycle moves to the right (and it follows or lags the base cycle). The base cycle for BC and the base cycle for FC must be set a-priori with restrictions $\delta_{i}=1$ and $\gamma_{\mathrm{BC}, i}=0$, for a specific variable $i$, and $\beta_{j}=1$ and $\gamma_{\mathrm{FC}, j}=0$, for a specific variable $j$, with $i, j=1, \ldots, p$. Due to the periodicity of trigonometric functions, $\gamma_{\mathrm{BC}, i}$ and $\gamma_{\mathrm{FC}, i}$ are restricted to the range $-\frac{1}{2} \pi / \lambda_{\mathrm{BC}}<\gamma_{\mathrm{BC}, i}<\frac{1}{2} \pi / \lambda_{\mathrm{BC}}$ and $-\frac{1}{2} \pi / \lambda_{\mathrm{FC}}<\gamma_{\mathrm{FC}, i}<\frac{1}{2} \pi / \lambda_{\mathrm{FC}}$.

The details of the model used in our empirical study of Section 4 are as follows. The first series in $\boldsymbol{y}_{t}$ is reserved for the key macroeconomic series of GDP to facilitate the identification of the business cycle. Hence the equation for GDP includes the base cycle BC but does not include $\mathrm{FC}$; we have $\delta_{1}=1, \gamma_{\mathrm{BC}, 1}=\beta_{1}=\gamma_{\mathrm{FC}, 1}=0$. The remaining variable equations for $\boldsymbol{y}_{t}$ include both cycles but the series placed second in $\boldsymbol{y}_{t}$ contains the base cycle for FC; we have $\beta_{2}=1$ and $\gamma_{\mathrm{FC}, 2}=0$. The remaining parameters and unobserved components are estimated simultaneously. For this purpose, we adopt the state space methods as presented and discussed in Durbin and Koopman (2012). It requires the formulation of the model as 
a linear Gaussian state space model and is presented next.

\subsection{Linear Gaussian state space model}

In order to formulate our decomposition model as a linear Gaussian state space model, we need to introduce some further notation. Let the vector of states $\boldsymbol{\alpha}_{t}$ consist of all unobserved trend and cycle components,

$$
\boldsymbol{\alpha}_{t}=\left(\begin{array}{llllllllll}
\mu_{1 t} & \nu_{1 t} & \ldots & \mu_{p t} & \nu_{p t} & \psi_{\mathrm{BC}, t} & \psi_{\mathrm{BC}, t}^{\star} & \psi_{\mathrm{FC}, t} & \psi_{\mathrm{FC}, t}^{\star}
\end{array}\right)^{\prime}
$$

By adopting the notation in, for example, Durbin and Koopman (2012, Part I), we can formulate our model as the linear Gaussian state space model given by

$$
\begin{aligned}
& \boldsymbol{y}_{t}=\boldsymbol{Z} \boldsymbol{\alpha}_{t}+\boldsymbol{\varepsilon}_{t}, \quad \boldsymbol{\varepsilon}_{t} \sim \mathrm{N}(\mathbf{0}, \boldsymbol{H}), \\
& \boldsymbol{\alpha}_{t+\mathbf{1}}=\boldsymbol{T} \boldsymbol{\alpha}_{t}+\boldsymbol{\eta}_{t}, \quad \boldsymbol{\eta}_{t} \sim \mathrm{N}(\mathbf{0}, \boldsymbol{Q}), \quad \boldsymbol{\alpha}_{1} \sim p(\cdot ; \boldsymbol{\theta}),
\end{aligned}
$$

where $\varepsilon_{t}=\left(\varepsilon_{1 t}, \ldots, \varepsilon_{p t}\right)^{\prime}$,

$$
\begin{array}{ll}
\boldsymbol{Z}=\left(\boldsymbol{Z}_{[\boldsymbol{\mu}]}, \boldsymbol{Z}_{[\psi]}\right), & \boldsymbol{H}=\operatorname{diag}\left[\sigma_{\varepsilon, 1}^{2}, \ldots, \sigma_{\varepsilon, p}^{2}\right], \\
\boldsymbol{T}=\operatorname{diag}\left[\boldsymbol{T}_{[\boldsymbol{\mu}]}, \boldsymbol{T}_{\left[\boldsymbol{\psi}_{\mathrm{BC}}\right]}, \boldsymbol{T}_{\left[\psi_{\mathrm{FC}}\right]}\right], & \boldsymbol{Q}=\operatorname{diag}\left[\boldsymbol{Q}_{[\boldsymbol{\mu}]}, \boldsymbol{Q}_{\left[\psi_{\mathrm{BC}}\right]}, \boldsymbol{Q}_{\left[\psi_{\mathrm{FC}}\right]}\right]
\end{array}
$$

with $(A, B)$ denoting the horizontal concatenation of the matrices $A$ and $B$, and $\operatorname{diag}[A, B]$ denoting the block diagonal matrix with matrices (or scalars) $A$ and $B$ on the diagonal. The 
submatrices are given by

$$
\begin{aligned}
& \boldsymbol{Z}_{[\boldsymbol{\mu}]}=\left[I_{p} \otimes\left(\begin{array}{ll}
1 & 0
\end{array}\right)\right], \quad \boldsymbol{T}_{[\boldsymbol{\mu}]}=I_{p} \otimes\left[\begin{array}{ll}
1 & 1 \\
0 & 1
\end{array}\right] \\
& \boldsymbol{Z}_{[\boldsymbol{\psi}}=\left[\begin{array}{cccc}
1 & 0 & 0 & 0 \\
\delta_{2} \cos \left(\gamma_{\mathrm{BC}, 2} \lambda_{\mathrm{BC}}\right) & \delta_{2} \sin \left(\gamma_{\mathrm{BC}, 2} \lambda_{\mathrm{BC}}\right) & 1 & 0 \\
\delta_{3} \cos \left(\gamma_{\mathrm{BC}, 3} \lambda_{\mathrm{BC}}\right) & \delta_{3} \sin \left(\gamma_{\mathrm{BC}, 3} \lambda_{\mathrm{BC}}\right) & \beta_{3} \cos \left(\gamma_{\mathrm{FC}, 3} \lambda_{\mathrm{FC}}\right) & \beta_{3} \sin \left(\gamma_{\mathrm{FC}, 3} \lambda_{\mathrm{FC}}\right) \\
\vdots & \vdots & \vdots & \vdots \\
\delta_{p} \cos \left(\gamma_{\mathrm{BC}, p} \lambda_{\mathrm{BC}}\right) & \delta_{p} \sin \left(\gamma_{\mathrm{BC}, p} \lambda_{\mathrm{BC}}\right) & \beta_{p} \cos \left(\gamma_{\mathrm{FC}, p} \lambda_{\mathrm{FC}}\right) & \beta_{p} \sin \left(\gamma_{\mathrm{FC}, p} \lambda_{\mathrm{FC}}\right)
\end{array}\right] \\
& \boldsymbol{T}_{\left[\psi_{\mathrm{BC}}\right]}=\phi_{\mathrm{BC}}\left[\begin{array}{rr}
\cos \lambda_{\mathrm{BC}} & \sin \lambda_{\mathrm{BC}} \\
-\sin \lambda_{\mathrm{BC}} & \cos \lambda_{\mathrm{BC}}
\end{array}\right], \quad \boldsymbol{T}_{\left[\psi_{\mathrm{FC}}\right]}=\phi_{\mathrm{FC}}\left[\begin{array}{rr}
\cos \lambda_{\mathrm{FC}} & \sin \lambda_{\mathrm{FC}} \\
-\sin \lambda_{\mathrm{FC}} & \cos \lambda_{\mathrm{FC}}
\end{array}\right] \\
& \boldsymbol{Q}_{[\boldsymbol{\mu}]}=\operatorname{diag}\left[\sigma_{\xi, 1}^{2}, \cdots, \sigma_{\xi, p}^{2}\right] \otimes\left[\begin{array}{cc}
0 & 0 \\
0 & 1
\end{array}\right], \quad \boldsymbol{Q}_{\left[\psi_{\mathrm{BC}}\right]}=\sigma_{\omega, \mathrm{BC}}^{2} I_{2}, \quad \boldsymbol{Q}_{\left[\psi_{\mathrm{FC}}\right]}=\sigma_{\omega, \mathrm{FC}}^{2} I_{2},
\end{aligned}
$$

with $I_{p}$ being the identity matrix of dimension $p$, and $\otimes$ denoting the Kronecker product. We notice that the specification of matrix $\boldsymbol{Z}_{[\boldsymbol{}}$ has accounted for the restrictions imposed for our empirical study.

For this empirical study, we have collected the unknown static parameters in the vector

$$
\begin{array}{r}
\boldsymbol{\theta}=\left\{\sigma_{\varepsilon, 1}^{2}, \ldots, \sigma_{\varepsilon, p}^{2}, \sigma_{\xi, 1}^{2}, \ldots, \sigma_{\xi, p}^{2}, \delta_{2}, \ldots, \delta_{p}, \beta_{3}, \ldots, \beta_{p}, \gamma_{\mathrm{BC}, 2}, \ldots, \gamma_{\mathrm{FC}, p}\right. \\
\left.\lambda_{\mathrm{BC}}, \lambda_{\mathrm{FC}}, \phi_{\mathrm{BC}}, \phi_{\mathrm{FC}}, \sigma_{\omega, \mathrm{BC}}^{2}, \sigma_{\omega, \mathrm{FC}}^{2}\right\} .
\end{array}
$$

For a given parameter vector $\boldsymbol{\theta}$, the loglikelihood value, the minimum mean square error (MMSE) estimates of $\boldsymbol{\alpha}_{t}$ and the forecasts for $\boldsymbol{y}_{t+h}$, for any $h>1$, can be obtained by the Kalman filter and smoother. The parameter vector $\boldsymbol{\theta}$ can subsequently be estimated by the numerical maximization of the loglikelihood function with respect to $\boldsymbol{\theta}$. Given the possibly large dimension of $\boldsymbol{\theta}$ we use several starting values for the maximization routine to prevent the risk of searching around local maxima of the loglikelihood function. All calculations are carried out with the software package OxMetrics of Doornik (2007) and the library of state space functions in Ssfpack, see Koopman, Shephard, and Doornik (2008). 


\section{Results of empirical study}

We present the estimation results for the financial cycle based on our macro finance data set presented in Section 2 and our modelling framework developed in Section 3. The observation vector $\boldsymbol{y}_{t}$ consists of five quarterly time series variables, that is $p=5$ and

$$
\boldsymbol{y}_{t}=(\mathrm{GDP}, \text { Credit }, \text { Credit-to-GDP }, \text { Credit-to-DPI, residential property prices })_{t}^{\prime} \text {, }
$$

for $t=1, \ldots, n$. We have constructed this data panel for four countries: United States (U.S.), Germany, France and United Kingdom (U.K.). The data sample stretches from 1970 to 2014 , that is $n=140$. The data panels are unbalanced which implies that we have many missing values. Our methods are based on the Kalman filter which enables us to treat missing values without much additional effort.

The parameters of the business cycle $\psi_{\mathrm{BC}, t}$ and the financial cycle $\psi_{\mathrm{BC}, t}$ are subject to one further mild restriction: the length of the business cycle is bounded between 1.5 and 12 years (compare the business cycle definitions of Burns and Mitchell (1946)) while the length of the financial cycle must be larger than 12 years. This restriction also implies that the two cycles have strictly different lengths. For Germany, we allow for a level shift in the trend component of Credit-to-DPI to account for a break in the DPI series in 1990 due to the German re-unification. Table 1 presents the parameter estimates.

The estimates of $\phi_{\mathrm{BC}} \approx 0.95$ and $\phi_{\mathrm{FC}} \approx 0.99$ reveal that both the business cycle and the financial cycle are highly persistent. In particular, the financial cycle is slowly varying. The business cycles have estimated lengths of $\frac{1}{2} \pi / \lambda_{\mathrm{BC}}=8.05$ years for the U.S., and 4.91, 8.75, and 11.99 years for France, U.K. and Germany, respectively. Except for Germany, the estimates appear to lie well below the 12 year bound that we have imposed during the estimation process. These estimates are similar to those obtained in earlier empirical work; see, for example, Galati et al. (2016). In the case of Germany, the data does not appear to give rise to a separate (idiosyncratic) business cycle with a much shorter cycle length. Even when we consider a univariate decomposition (trend plus cycle) model for GDP only, the estimated cycle has a relatively long period, between 13 and 14 years.

It is an interesting finding that the extracted financial cycles have typically around twice (or more) the length of the business cycle. For the U.S. we have estimated a financial cycle length of $\frac{1}{2} \pi / \lambda_{\mathrm{FC}}=16.84$ years, while we have estimated cycle lengths of $23.72,18.29$, and 26.14 for France, U.K., and Germany, respectively. For France, the estimated length of the financial cycle is more than four times the length of the business cycle. Still, this estimate is similar to the estimates of the other three countries in our study. It appears that also 
Table 1: Maximum likelihood estimates of the parameter vector $\boldsymbol{\theta}$ for United States (U.S.), Germany (GER), France (FR) and United Kingdom (U.K.). The numbered subscripts of the parameters refer to 1=GDP, $2=$ Credit, $3=$ Credit-to-GDP, $4=$ Credit-to-DPI, and $5=$ Property. Standard errors are given in parenthesis and ${ }^{*},{ }^{*}$ denote significance at the $5 \%$ and $1 \%$ level, respectively. Although the data is quarterly, the estimated periods and phase shfits of the cycles are presented in years for clarity.

\begin{tabular}{|c|c|c|c|c|c|c|c|}
\hline & $\delta_{2}$ & $\delta_{3}$ & $\delta_{4}$ & $\delta_{5}$ & $\beta_{3}$ & $\beta_{4}$ & $\beta_{5}$ \\
\hline U.S. & $\begin{array}{c}0.985^{* *} \\
(0.066)\end{array}$ & $\begin{array}{c}0.301^{* *} \\
(0.041)\end{array}$ & $\begin{array}{c}0.110^{* *} \\
(0.025)\end{array}$ & $\begin{array}{c}0.514^{* *} \\
(0.137)\end{array}$ & $\begin{array}{c}0.696^{* *} \\
(0.018)\end{array}$ & $\begin{array}{c}0.191^{* *} \\
(0.025)\end{array}$ & $\begin{array}{c}0.900^{* *} \\
(0.147)\end{array}$ \\
\hline GER & $\begin{array}{l}1.026^{* *} \\
(0.057)\end{array}$ & $\begin{array}{c}2.263^{* *} \\
(0.312)\end{array}$ & $\begin{array}{c}1.766^{* *} \\
(0.300)\end{array}$ & $\begin{array}{c}0.259^{* *} \\
(0.104)\end{array}$ & $\begin{array}{l}4.625^{* *} \\
(0.091)\end{array}$ & $\begin{array}{c}7.752^{* *} \\
(0.503)\end{array}$ & $\begin{array}{c}0.615^{* *} \\
(0.069)\end{array}$ \\
\hline FR & $\begin{array}{l}1.080^{* *} \\
(0.055)\end{array}$ & $\begin{array}{c}0.939^{* *} \\
(0.068)\end{array}$ & $\begin{array}{c}1.347^{* *} \\
(0.230)\end{array}$ & $\begin{array}{c}0.299^{* *} \\
(0.136)\end{array}$ & $\begin{array}{c}5.195^{* *} \\
(0.106)\end{array}$ & $\begin{array}{c}1.784^{* *} \\
(0.112)\end{array}$ & $\begin{array}{c}0.082 \\
(0.064)\end{array}$ \\
\hline U.K. & $\begin{array}{c}1.114^{* *} \\
(0.144)\end{array}$ & $\begin{array}{c}2.175^{* *} \\
(0.210)\end{array}$ & $\begin{array}{c}4.596^{* *} \\
(1.208)\end{array}$ & $\begin{array}{c}0.747^{* *} \\
(0.226)\end{array}$ & $\begin{array}{c}4.255^{* *} \\
(0.143)\end{array}$ & $\begin{array}{c}6.022^{* *} \\
(0.596)\end{array}$ & $\begin{array}{c}0.211 \\
(0.228)\end{array}$ \\
\hline & $\gamma_{\mathrm{BC}, 2}$ & $\gamma_{\mathrm{BC}, 3}$ & $\gamma_{\mathrm{BC}, 4}$ & $\gamma_{\mathrm{BC}, 5}$ & $\gamma_{\mathrm{FC}, 2}$ & $\gamma_{\mathrm{FC}, 4}$ & $\gamma_{\mathrm{FC}, 5}$ \\
\hline U.S. & $\begin{array}{c}-0.659^{* *} \\
(0.154)\end{array}$ & $\begin{array}{c}-2.013^{* *} \\
(0.284)\end{array}$ & $\begin{array}{c}-1.010^{* *} \\
(0.289)\end{array}$ & $\begin{array}{c}0.771 \\
(0.451)\end{array}$ & $\begin{array}{c}0.332^{* *} \\
(0.064)\end{array}$ & $\begin{array}{c}0.305 \\
(0.380)\end{array}$ & $\begin{array}{c}-1.158 \\
(0.626)\end{array}$ \\
\hline GER & $\begin{array}{c}-0.955^{* *} \\
(0.212)\end{array}$ & $\begin{array}{c}-3.000^{* *} \\
(0.407)\end{array}$ & $\begin{array}{c}-1.320^{* *} \\
(0.618)\end{array}$ & $\begin{array}{c}0.945 \\
(0.491)\end{array}$ & $\begin{array}{c}0.776 \\
(0.858)\end{array}$ & $\begin{array}{c}-0.043 \\
(0.054)\end{array}$ & $\begin{array}{c}6.532^{* *} \\
(1.450)\end{array}$ \\
\hline $\mathrm{FR}$ & $\begin{array}{c}-0.097 \\
(0.218)\end{array}$ & $\begin{array}{c}-1.228^{* *} \\
(0.101)\end{array}$ & $\begin{array}{c}-0.279^{*} \\
(0.141)\end{array}$ & $\begin{array}{c}-0.049 \\
(0.513)\end{array}$ & $\begin{array}{c}0.017 \\
(0.075)\end{array}$ & $\begin{array}{c}1.970^{* *} \\
(0.571)\end{array}$ & $\begin{array}{c}3.655 \\
(2.946)\end{array}$ \\
\hline U.K. & $\begin{array}{c}0.155 \\
(0.208)\end{array}$ & $\begin{array}{c}-2.187^{* *} \\
(0.254)\end{array}$ & $\begin{array}{c}-0.996^{* *} \\
(0.156)\end{array}$ & $\begin{array}{c}-0.444 \\
(0.585)\end{array}$ & $\begin{array}{l}-0.227 \\
(0.312)\end{array}$ & $\begin{array}{c}1.404^{* *} \\
(0.447)\end{array}$ & $\begin{array}{c}-18.288^{* *} \\
(1.612)\end{array}$ \\
\hline & $\frac{1}{2} \pi / \lambda_{\mathrm{BC}}$ & $\frac{1}{2} \pi / \lambda_{\mathrm{FC}}$ & $\phi_{\mathrm{BC}}$ & $\phi_{\mathrm{FC}}$ & $\begin{array}{c}100 \times \\
\sigma_{\omega, \mathrm{BC}} \\
\end{array}$ & $\begin{array}{c}100 \times \\
\sigma_{\omega, \mathrm{FC}} \\
\end{array}$ & \\
\hline U.S. & $\begin{array}{c}8.054^{* *} \\
(1.114)\end{array}$ & $\begin{array}{c}16.840^{* *} \\
(2.074)\end{array}$ & $\begin{array}{c}0.953^{* *} \\
(0.016)\end{array}$ & $\begin{array}{c}0.990^{* *} \\
(0.006)\end{array}$ & $\begin{array}{c}0.682^{* *} \\
(0.039)\end{array}$ & $\begin{array}{c}0.717^{* *} \\
(0.041)\end{array}$ & \\
\hline GER & $\begin{array}{c}11.990^{* *} \\
(1.473)\end{array}$ & $\begin{array}{c}26.138^{* *} \\
(4.384)\end{array}$ & $\begin{array}{c}0.940^{* *} \\
(0.025)\end{array}$ & $\begin{array}{c}0.990^{* *} \\
(0.006)\end{array}$ & $\begin{array}{c}0.011^{* *} \\
(0.001)\end{array}$ & $\begin{array}{c}0.903^{* *} \\
(0.049)\end{array}$ & \\
\hline FR & $\begin{array}{l}4.914^{* *} \\
(0.564)\end{array}$ & $\begin{array}{c}23.717^{* *} \\
(5.777)\end{array}$ & $\begin{array}{c}0.941^{* *} \\
(0.020)\end{array}$ & $\begin{array}{c}0.979^{* *} \\
(0.012)\end{array}$ & $\begin{array}{c}0.353^{* *} \\
(0.025)\end{array}$ & $\begin{array}{c}0.964^{* *} \\
(0.058)\end{array}$ & \\
\hline U.K. & $\begin{array}{l}8.750^{* *} \\
(1.075)\end{array}$ & $\begin{array}{c}18.290^{* *} \\
(2.217)\end{array}$ & $\begin{array}{c}0.952^{* *} \\
(0.016)\end{array}$ & $\begin{array}{c}0.992^{* *} \\
(0.006)\end{array}$ & $\begin{array}{c}0.734^{* *} \\
(0.042)\end{array}$ & $\begin{array}{c}0.015^{* *} \\
(0.001)\end{array}$ & \\
\hline
\end{tabular}

for our model-based approach, we find clear evidence of cyclical behaviour in macro-finance related data above and beyond business cycle fluctuations. This finding is consistent with the results from pure filtering based approaches such as those of Drehmann et al. (2012) and Borio (2014).

The extracted cycles are visualized in Figures 1 and 2. When we investigate the extracted business cycle for the U.S., we encounter the familiar pattern: our model-based business cycle indicator declines during the periods classified as recessions by the NBER; these are the grey areas in Figure 1. It is revealing that the extracted business cycles are quite different 
US

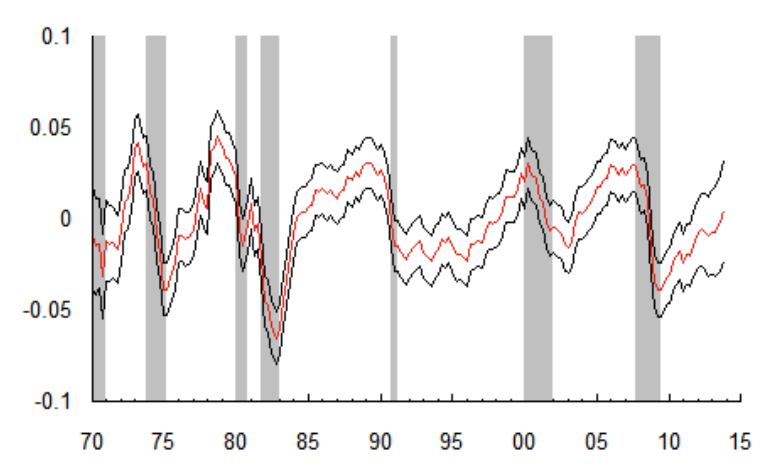

FR

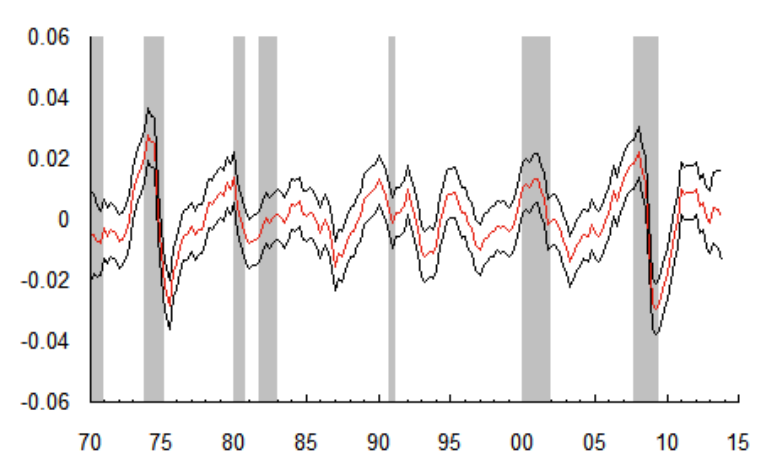

GER

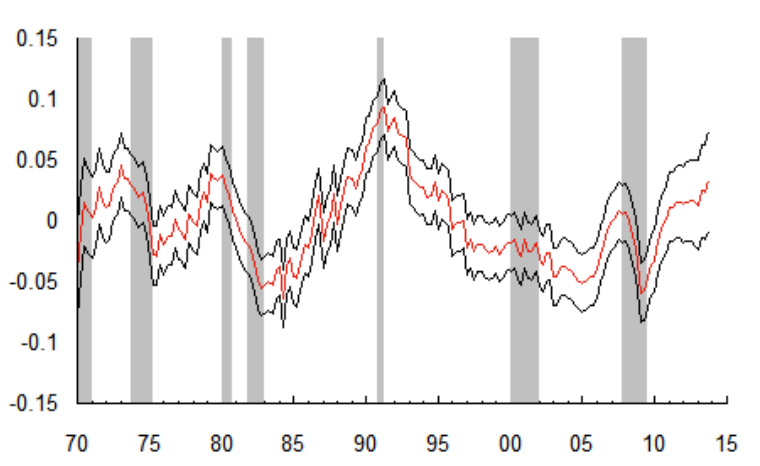

UK

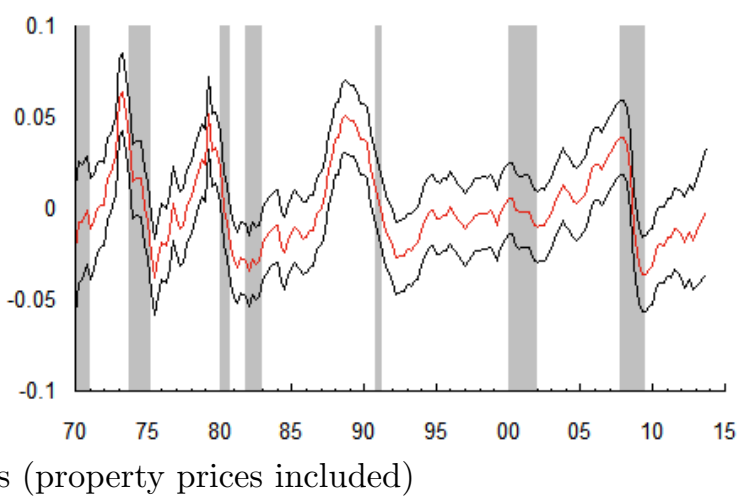

across our four selected countries. This also holds for the three European countries. For example, cyclical movements in France during the 1990s were much more pronounced than those obtained for the U.S. and U.K., whereas the trough in the early 1980s was much less deep. Conversely, the business cycle rebound after the financial crisis of 2008-2009 was much stronger in France and Germany when compared to the rebound in the U.K. or the U.S. This underlines the need to allow for heterogeneity across countries in the cyclical movements, despite the global economic integration processes that have taken place over this period.

Our estimated financial cycle indicators in Figure 2 show that the cyclical movements in the financial variables are much longer overall when compared to those of the business cycles. The cross-country heterogeneity of these results is even more noticeable in this case. The movements between the U.S. and U.K. largely coincide, with the financial cycle in the U.S. in the 1980s-1990s peaking about 3 years before the one in the U.K. The financial cycle for France peaks 3 to 4 years later, around 1994, but does not show a similar build-up towards 2008 as we can observe this build-up for the financial cycles for the U.K. and U.S. The results for Germany are quite different. After the German re-unification, the financial cycle rises steadily during the 1990s, but declines afterwards rather than building up to the financial crisis of 2008. The recent financial crisis is only noticeable as a small increase, after which 
US

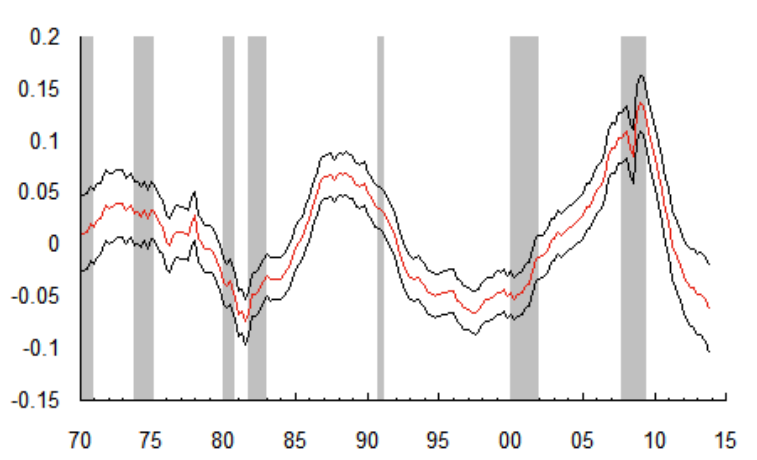

FR

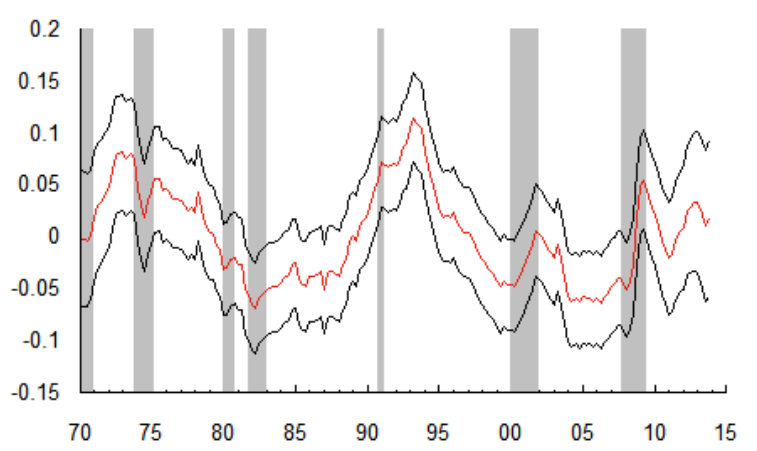

GER

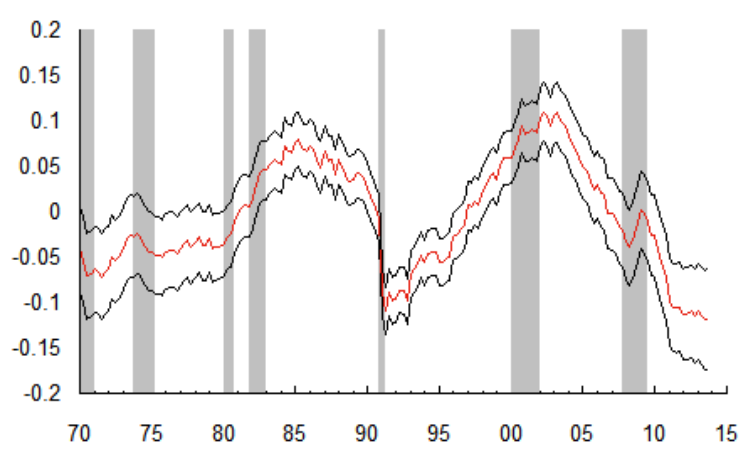

UK

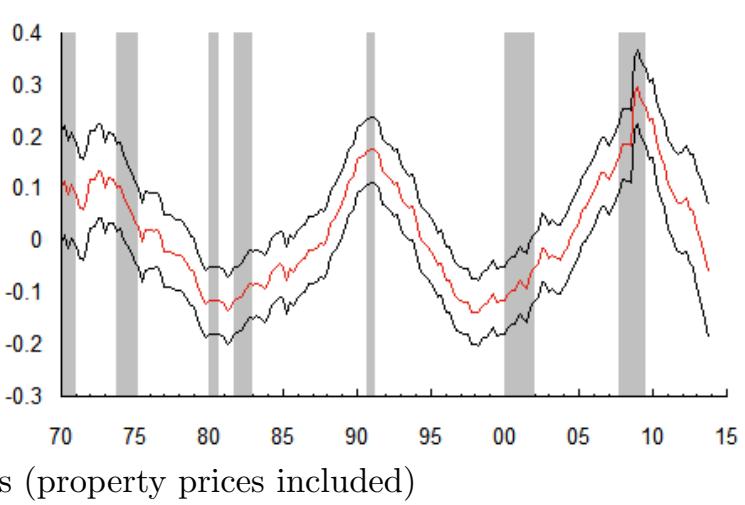

the downward trend in the financial cycle continues. It is clear from these patterns that further important cyclical patterns are clearly present in the time series above and beyond the business cycle dynamics. Economic policy targeted at financial stability can therefore not exclusively focus on business cycle dynamics. It appears that longer swings in financial key ratios also contribute to unhinging systemic stability.

The business cycle and the financial cycle enter each variable in our decomposition model via the parameters $\gamma_{\mathrm{BC} / \mathrm{FC}, i}$. The cycle for each separate variable is not simply a linear combination of $\psi_{\mathrm{BC} / \mathrm{FC}, t}$, but it is a linear combination of both $\psi_{\mathrm{BC} / \mathrm{FC}, t}$ and $\psi_{\mathrm{BC} / \mathrm{FC}, t}^{\star}$ as indicated in equations (5) and (6). The estimated $\delta_{i}$ coefficients in Table 1 indicate that the business cycle affects all variables included in the model. Given the negative $\gamma_{\mathrm{BC}, i}$ estimates, most of the financial variables lag the business cycle by 1 to 3 quarters, whereas the total amount of credit for France and the U.K. appears to be contemporaneously linked with the business cycle. We regard it as an interesting and insightful empirical finding that property prices appear to be largely coincidental with the business cycle for all countries in the sample.

The aberrant behaviour of property prices is reinforced when we consider the estimated $\beta_{i}$ coefficients which indicate how the financial variables load on the common financial cycle. Property prices appear to be the only financial variable in the model that does not load 
strongly on the financial cycle. Whereas the $\gamma_{\mathrm{FC}, i}$ estimates are close to zero for most financial variables, they are substantial and sometimes even significant for property prices. This is remarkable, because most previous empirical studies on the financial cycle have included property prices as a key variable for the financial cycle using standard filtering techniques such as the Hodrick-Prescott filter or the Christiano-Fitzgerald filter; see, for example, Strohsal et al. (2015), Drehmann et al. (2012), Galati et al. (2016) and Claessens et al. (2011). Our model-based empirical results reveal that the cyclical movements in property prices may not be so easily reconciled with the cycles in credit related variables. It is important to be aware of this when financial cycle estimates are to be used for systemic risk surveillance.

To investigate the robustness of our estimates of the financial cycle to the inclusion of the apparently aberrant property prices series, we have re-estimated parameters in our model specification but for four variables $(p=4)$, thus leaving out property prices. Comparing these results (which are not shown but can be provided upon request) with those in Figures 1 and 2 , the results present a very similar picture and the conclusions largely coincide. The only apparent difference is that the business cycle for the U.K. after the financial crisis now appears to rebound more in line with the other two European countries in the sample, France and Germany. The effect on the financial cycle estimates of leaving out property prices, however, appears negligible, thus reinforcing our previous results and conclusions.

Finally, it is interesting to investigate which part of the cyclical variation in our panel of time series is explained by the business cycle versus the financial cycle. For this purpose, we compute the unconditional variances of both components for each series and report their proportions in Table 2. The unconditional variances for the cycles can be derived from equation (3) and we obtain

$$
\sigma_{\psi_{\mathrm{BC}, i t}}^{2}=\sigma_{\omega, \kappa}^{2} /\left(1-\phi_{\kappa}^{2}\right)
$$

for $\kappa \in\{\mathrm{BC}, \mathrm{FC}\}$. This variance has to be multiplied by the square of the loading coefficient $\beta_{i}$ or $\delta_{i}$. It is implied by the identification restrictions that the business cycle explains $100 \%$ of the cyclical variation of the GDP series. We further find that the business cycle only has a very modest contribution to the credit related variables. Particularly for the credit related ratios, the contributions of the business cycle component remain below $6 \%$. The financial cycle thus appears to be an important part of the credit related variables, and its dynamics are substantially different from those of the business cycle. Systemic surveillance should thus account for both types of dynamics when designing adequate policies. 
Table 2: Proportions of the business cycle and financial cycle in the cyclical variance of each series

\begin{tabular}{|c|c|c|c|c|c|c|c|c|}
\hline & \multicolumn{2}{|c|}{ U.S. } & \multicolumn{2}{|c|}{ Germany } & \multicolumn{2}{|c|}{ France } & \multicolumn{2}{|c|}{ U.K. } \\
\hline & $\mathrm{BC}$ & $\mathrm{FC}$ & $\mathrm{BC}$ & $\mathrm{FC}$ & $\mathrm{BC}$ & $\mathrm{FC}$ & $\mathrm{BC}$ & $\mathrm{FC}$ \\
\hline GDP & $100 \%$ & $0 \%$ & $100 \%$ & $0 \%$ & $100 \%$ & $0 \%$ & $100 \%$ & $0 \%$ \\
\hline Credit & $16 \%$ & $84 \%$ & $21 \%$ & $79 \%$ & $5 \%$ & $95 \%$ & $5 \%$ & $95 \%$ \\
\hline Credit-to-GDP & $3 \%$ & $97 \%$ & $6 \%$ & $94 \%$ & $0 \%$ & $100 \%$ & $0 \%$ & $100 \%$ \\
\hline Credit-to-DPI & $6 \%$ & $94 \%$ & $1 \%$ & $99 \%$ & $3 \%$ & $97 \%$ & $1 \%$ & $99 \%$ \\
\hline
\end{tabular}

\section{Conclusions}

We have developed a multivariate unobserved components model to construct a modelbased decomposition of a panel of economic time series into a set of smooth trends, a country specific business cycle and a country specific financial cycle. Our approach provides a modelbased alternative to earlier estimates of the financial cycle based on standard macro filtering techniques such as the Hodrick-Prescot filter. The cycles in our approach vary stochastically over time and can be subject to different scalings and phase shifts for different economic series. Our framework is therefore much more flexible than the filtering approaches while still targeting a common financial cycle for each specific country using the relevant macro finance variables.

In our empirical analysis, we have focused on four large economies: the United States, Germany, France, and the United Kingdom. For a data panel with GDP information, credit related variables and property prices, we have found statistically significant evidence of the existence of a financial cycle. The length of the financial cycle typically is around twice as long as that of the business cycle. The dynamics of the financial cycle also appear to be quite distinct from the business cycle dynamics: less than $6 \%$ of the cyclical variation in credit related quantities is explained by the business cycle. The remainder can be attributed to the financial cycle. We therefore conclude that the dynamics of a financial cycle should be taken into account when designing systemic surveillance policies.

Finally, our results point out that property prices may be subject to different cyclical dynamics. Using our model-based approach, property prices appear to load only marginally on either the business cycle or the financial cycle. This finding appears to be in contrast with earlier literature where property prices are routinely included in the analysis for the estimation of the financial cycle. Such a routine inclusion may bias the estimates of the financial cycle and should therefore be interpreted with care. 


\section{References}

Baxter, M. and R. G. King (1999). Measuring business cycles: Approximate band-pass filters for economic time series. The Review of Economics and Statistics 81(4), 575-593.

Bernanke, B. S. and A. S. Blinder (1992). The federal funds rate and the channels of monetary transmission. American Economic Review 82, 901-921.

Beveridge, S. and C. R. Nelson (1981). A new approach to decomposition of economic time series into permanent and transitory components with particular attention to measurement of the business cycle. Journal of Monetary Economics 7, 151-174.

Borio, C. (2014). The financial cycle and macroeconomics: What have we learnt? Journal of Banking $\mathcal{G}$ Finance 45, 182-198.

Burns, A. F. and W. C. Mitchell (1946). Measuring Business Cycles. National Bureau of Economic Research.

Christiano, L. J. and T. J. Fitzgerald (2003). The band pass filter. International Economic Review 44(2), $435-465$.

Claessens, S., M. Ayhan Kose, and M. E. Terrones (2011). Financial cycles: What? how? when? In NBER International Seminar on Macroeconomics 2010, pp. 303-343. Chicago: University of Chicago Press.

Clark, P. K. (1987). The cyclical component of U.S. economic activity. Quarterly Journal of Economics 102(4), 797-814.

Doornik, J. A. (2007). Object-Oriented Matrix Programming Using Ox, 3rd ed. London: Timberlake Consultants Press.

Drehmann, M., C. Borio, and K. Tsatsaronis (2012). Characterizing the financial cycle: don't lose sight of the medium term! Discussion paper, Bank for international settlements.

Durbin, J. and S. J. Koopman (2012). Time Series Analysis by State Space Methods (2nd ed.). Oxford: Oxford University Press.

Galati, G., I. Hindrayanto, S. J. Koopman, and M. Vlekke (2016). Measuring financial cycles in a modelbased analysis: Empirical evidence for the United States and the Euro area. Economics Letters 172, forthcoming.

Harvey, A. C. (1989). Forecasting, Structural Time Series Models and the Kalman Filter. Cambridge: Cambridge University Press.

Harvey, A. C. and A. Jaeger (1993). Detrending, stylised facts and the business cycle. Journal of Applied Econometrics 8, 231-247.

Harvey, A. C. and T. M. Trimbur (2003). General model-based filters for extracting cycles and trends in economic time series. The Review of Economics and Statistics 85(2), 244-255.

Hodrick, R. J. and E. C. Prescott (1980). Postwar U.S. business cycles: an empirical investigation. Discussion paper 451, Carnegie-Mellon University. 
Koopman, S. J., N. Shephard, and J. A. Doornik (2008). SsfPack 3.0: Statistical algorithms for models in state space form. London: Timberlake Consultants Press.

Krolzig, H. M. (1997). Markov Switching Vector Autoregressions. Modelling, Statistical Inference and Application to Business Cycle Analysis. Berlin: Springer.

Morley, J. C., C. R. Nelson, and E. Zivot (2003). Why are the Beveridge-Nelson and unobserved-components decompositions of GDP so different? The Review of Economics and Statistics 85(2), 235-243.

Rünstler, G. (2004). Modelling phase shifts among stochastic cycles. Econometrics Journal 7, 232-248.

Sims, C. A. (1980). Macroeconomics and reality. Econometrica 48, 1-48.

Stock, J. H. and M. W. Watson (1999). Business cycle fluctuations in U.S. macroeconomic time series. In J. B. Taylor and M. Woodford (Eds.), Handbook of Macroeconomics, Volume 1A, pp. 3-64. North-Holland: Elsevier.

Strohsal, T., C. R. Proaño, and J. Wolters (2015). Characterizing the financial cycle: evidence from a frequency domain analysis. Discussion paper, Deutsche Bundesbank.

Valle e Azevedo, J. (2011). A multivariate band-pass filter for economic time series. Applied Statistics 60(1), $1-30$.

Valle e Azevedo, J., S. J. Koopman, and A. Rua (2006). Tracking the business cycle of the Euro area: a multivariate model-based band-pass filter. J. Business and Economic Statist. 24(3), 278-290. 